\title{
PRECIPITATION OF CAPSICUM PEPPER ETHANOLIC EXTRACT AND POLY(L-LACTIC ACID) BY SUPERCRITICAL $\mathrm{CO}_{2}$ ANTISOLVENT PROCESS
}

\author{
A. C. de AGUIAR ${ }^{1}$, F. M. BARRALES ${ }^{1}$, C. A. REZENDE ${ }^{2}$, G. F. BARBERO ${ }^{3}$, J. \\ MARTÍNEZ ${ }^{1}$ \\ ${ }^{1}$ University of Campinas, College of Food Engineering \\ ${ }^{2}$ University of Campinas, Institute of Chemistry \\ ${ }^{3}$ University of Cádiz, Department of Analytical Chemistry \\ Contact email: julian@fea.unicamp.br
}

\begin{abstract}
Biquinho pepper is rich in capsinoids, which present strong pharmacological effects on health. The lack of pungency assigned to capsinoids make them interesting for the application in pharmaceutical and food industries. The aim of this work was to evaluate the encapsulation of biquinho extracts by supercritical antisolvent technique using Poly(L-lactic acid) as the coating material. A lab-scale apparatus that consists of a $\mathrm{CO}_{2}$ supply system, solution and $\mathrm{CO}_{2}$ injection unit (coaxial nozzle with an internal diameter equal to 127 $\mu \mathrm{m})$, and a high pressure column was used. The process parameters were: temperature and $\mathrm{CO}_{2}$ flow rate were fixed at $40{ }^{\circ} \mathrm{C}$ and $20.4 \mathrm{~g} / \mathrm{min}$ respectively, pressure varied from 8 to $12 \mathrm{MPa}$, and solution flow rate varied from 0.5 and $1.0 \mathrm{~mL} / \mathrm{min}$. The morphology of particles was analyzed using a scanning electron microscope. The micrographies showed that the geometry of the particles was greatly influenced by pressure and solution flow rate. At the conditions of $10 \mathrm{MPa}$ and $0.75 \mathrm{~mL} / \mathrm{min}$ solution flow rate, small spherical particles (diameter of approximately 5-10 $\mu \mathrm{m}$ ) were observed.
\end{abstract}

\section{INTRODUCTION}

Hot cultivars of Capsicum peppers are rich in capsaicinoids, which are the compounds responsible for the spicy flavor imparted by many peppers. Capsaicinoids have strong pharmacological effects on health, which may be used in pain relief, cancer prevention, and weight reduction (Luo et al., 2011).

A similar group of compounds named capsinoids (naturally occurring in some varieties of sweet peppers) seem to have similar effects to those of capsaicinoids, without presenting pungency (Hursel and Westerterp-Plantenga, 2010). These compounds have an ester bond instead of the amide bond between the vanillyl moiety and fatty acid chain normally found in capsaicinoids (Kobata et al., 1998). Known capsinoids include capsiate (CTE), dihydrocapsiate (DHCTE), and nordihydrocapsiate (n-DHCTE). Capsinoids are more unstable than the capsaicinoids: they are labile in polar solvents and probably tend to decompose in protic solvents, such as ethanol and water (Sutoh et al., 2001). Accordingly, the microencapsulation of these compounds can be an alternative to increase stability and ensure protection of their properties. Microparticle drug delivery systems have attracted 
great attention in recent years, since they allow increasing bioavailability, provide sustained release and reduce the side effects of drugs (Hoffman, 2008).

Traditional encapsulation methods include the emulsification/solvent evaporation (Rogers et al., 2002), jet milling (Schlocker et al., 2006), spray drying (Vehring, 2008) and freeze drying (Semyonov et al., 2010). However, these methods may present limitations, such as relatively large particle size, wide particle size distribution, degradation of the product and difficulties in complete recovery of organic solvents (Wang et al., 2013). The use of supercritical $\mathrm{CO}_{2}$ can be an alternative to overcome the drawbacks of conventional encapsulation methods, and presents many advantages for different applications, such as near ambient operating temperatures, efficient separation, very low or no organic solvent residue, and being environmentally safe solvent (Hakuta et al., 2003, Jung and Perrut, 2001).

As described by Cocero et al. (2009), supercritical antisolvent processes (SAS) are based on bringing into contact a solution of the solutes of interest (eg. drug and polymer) in a conventional liquid solvent with a supercritical fluid. Upon mixing, the supercritical fluid saturates the liquid solvent and depletes it by extraction. The saturation of the liquid solvent causes the precipitation of the solute by an antisolvent effect, resulting in the particle precipitation.

To the best of our knowledge, the co-precipitation study involving extracts from Capsicum peppers by supercritical antisolvent extraction has not been previously reported in the literature. Therefore, the aim of this work is to co-precipitate the alcoholic extract of biquinho pepper (BPE), a Brazilian sweet pepper with capsinoids in its composition, and Poly(L-lactic acid) (PLLA) by the SAS process using ethyl acetate as co-solvent and $\mathrm{CO}_{2}$ as antisolvent.

\section{MATERIAL AND METHODS}

\subsection{Chemicals and samples}

Approximately $5 \mathrm{~kg}$ of ripe Biquinho pepper were purchased at a local market in Campinas, Brazil. The antisolvent used in the SAS process was $\mathrm{CO}_{2}$ (White Martins, Campinas, SP, Brazil) with $99.0 \%$ purity. PLLA was purchased from Sigma Aldrich (Saint Louis, USA). All the other solvents and chemicals were of analytical grade.

\subsection{Preparation of the ethanolic extract from Biquinho pepper (BPE)}

The ethanolic extract of biquinho pepper (BPE) was obtained by ultrasound-assisted extraction. The extraction process consisted of transferring $25 \mathrm{~g}$ of lyophilized and ground pepper into $500 \mathrm{~mL}$ of ethanol. The mixture was then subjected to an ultrasonic probe and processed under ultrasonic power of $360 \mathrm{~W}$ for 10 minutes. The ultrasonic system used (Unique Group, model DES500, Campinas, Brazil) is composed by a transducer unit with frequency of $20 \mathrm{kHZ}$ and a variable output power controller. The mixture resulting from the extraction process was separated by filtration and was subsequently employed in the precipitation assays by SAS. 


\subsection{Apparatus and procedure for particles formation}

The experimental SAS apparatus shown schematically in Figure 1 consists of a $\mathrm{CO}_{2}$ supply system, a liquid injection unit, and a high pressure stainless steel column. Briefly, $\mathrm{CO}_{2}$, previously cooled in a thermostatic bath (MA184, Marconi, Campinas, Brazil) at -10 ${ }^{\circ} \mathrm{C}$, was pressurized using a pneumatic pump (PP 111-VE MBR, Maximator, Nordhausen, Germany) and subsequently heated to operating temperature in a heating bath (MA184, Marconi, Campinas, Brazil). Then, $\mathrm{CO}_{2}$ was injected into the high pressure column with flow rate controlled by a heated micrometer valve coupled to a rotameter used as gas flow meter. The internal temperature of the column was maintained by using the heating bath. After temperature and pressure were stabilized, the operation solution (pure PLLA or PLLA+ BPE solubilized in ethyl acetate) was introduced to the high pressure column using a HPLC pump (PU-2080, Jasco, Tokyo, Japan) through a coaxial nozzle with internal diameter of $127 \mu \mathrm{m}$. At the column inlet, previously saturated with supercritical $\mathrm{CO}_{2}$, rapid diffusion occurs at the cosolvent ethyl acetate and supercritical $\mathrm{CO}_{2}$. After the injection of the solution $(40 \mathrm{~mL})$, the system was kept under the same operation conditions to remove the residual organic solvent from the particles for $30 \mathrm{~min}$. Afterwards, the vessel was slowly depressurized and then the particles were collected in petri plates, sealed and stored under refrigeration.

First, PLLA was precipitated without addition of BPE, at the pressures of 8 and 12 $\mathrm{MPa}$ and flow rates of feed solution $\left(\mathrm{Q}_{\mathrm{sol}}\right)$ of 0.5 and $1 \mathrm{~mL} / \mathrm{min}$. The other parameters (temperature $\left(40{ }^{\circ} \mathrm{C}\right)$, PLLA solution concentration $\left(0.5 \%\right.$, w/v) and $\mathrm{CO}_{2}$ flow rate $(20.4$ $\mathrm{g} / \mathrm{min}$ )) were kept constant. Then, the precipitation of PLLA with BPE was conducted at the pressures and flow rates of feed solution presented in Table 1. The other process parameters were kept constant at the same levels applied for precipitation of pure PLLA.

Table 1 - Experimental condition for SAS process

\begin{tabular}{ccc}
\hline Exp & $\begin{array}{c}\text { Pressure } \\
(\mathrm{MPa})\end{array}$ & Flow rate of feed solution $(\mathrm{mL} / \mathrm{min})$ \\
\hline 1 & 8 & 0.5 \\
2 & 8 & 1.0 \\
3 & 12 & 0.5 \\
4 & 12 & 1.0 \\
5 & 10 & 0.75 \\
6 & 10 & 0.75 \\
7 & 10 & 0.75 \\
\hline
\end{tabular}




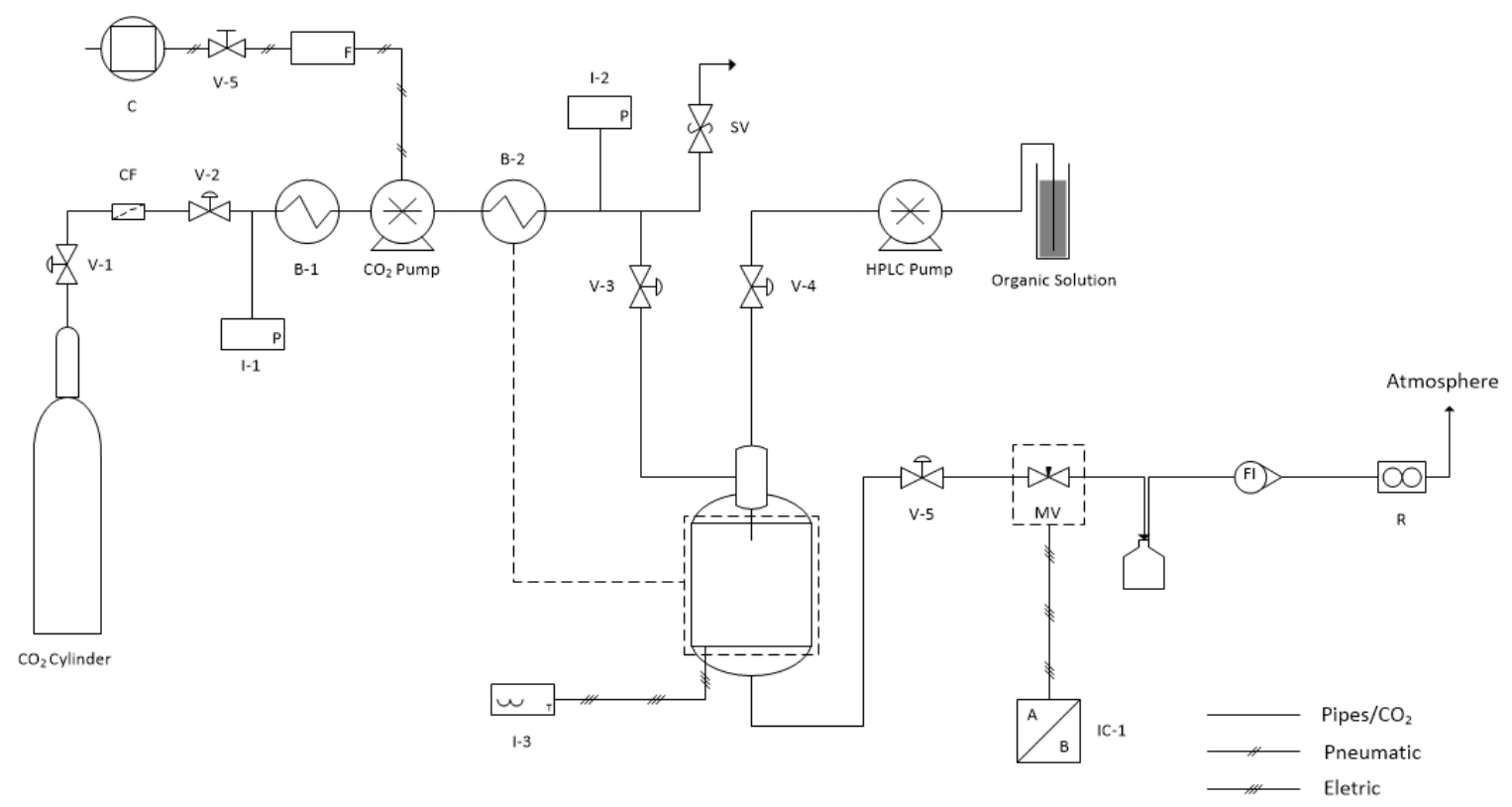

Figure 1 - Experimental apparatus in SAS configuration.

V-1, V-2, V-3, V-4 and V-5 - Control valves; MV - Micrometer valve; SV - Safety valve;

C- Compressor; F- Compressed air filter; $\mathrm{CF}-\mathrm{CO}_{2}$ Filter; B1 -Cooling bath; B2 - Heating bath; I-1 e I-2 - Pressure indicators; I-3 - Temperature indicator; IC-1 - Indicators and controllers of temperature of micrometer valve, $\mathrm{FL}$ - Rotameter; $\mathrm{R}$ - Gas totalizer.

\subsection{Particle characterization} below:

The particles morphology were determined according to the analisys described

Morphology: The morphology of the particles was analyzed using a scanning electron microscope equipped with a field emission gun (FESEM - FEI Quanta 650). Prior to analysis, the samples were coated with gold in a SCD 050 sputter coater (Oerlikon-Balzers, Balzers, Liechtenstein). Both equipments were available at the National Laboratory of Nanotechnology (LNNano, Campinas-SP, Brazil). Analyses of the sample surfaces were performed under vacuum, using a $5 \mathrm{kV}$ acceleration voltage and a large number of images were obtained on different areas of the samples to assure the reproducibility of the results.

\section{RESULTS AND DISCUSSION}

From an initial visual observation, all the precipitation assays (for pure PLLA and PLLA + BPE mixture) resulted in the formation of powder, with different colors and degrees of agglomeration, depending on the operating conditions employed. 

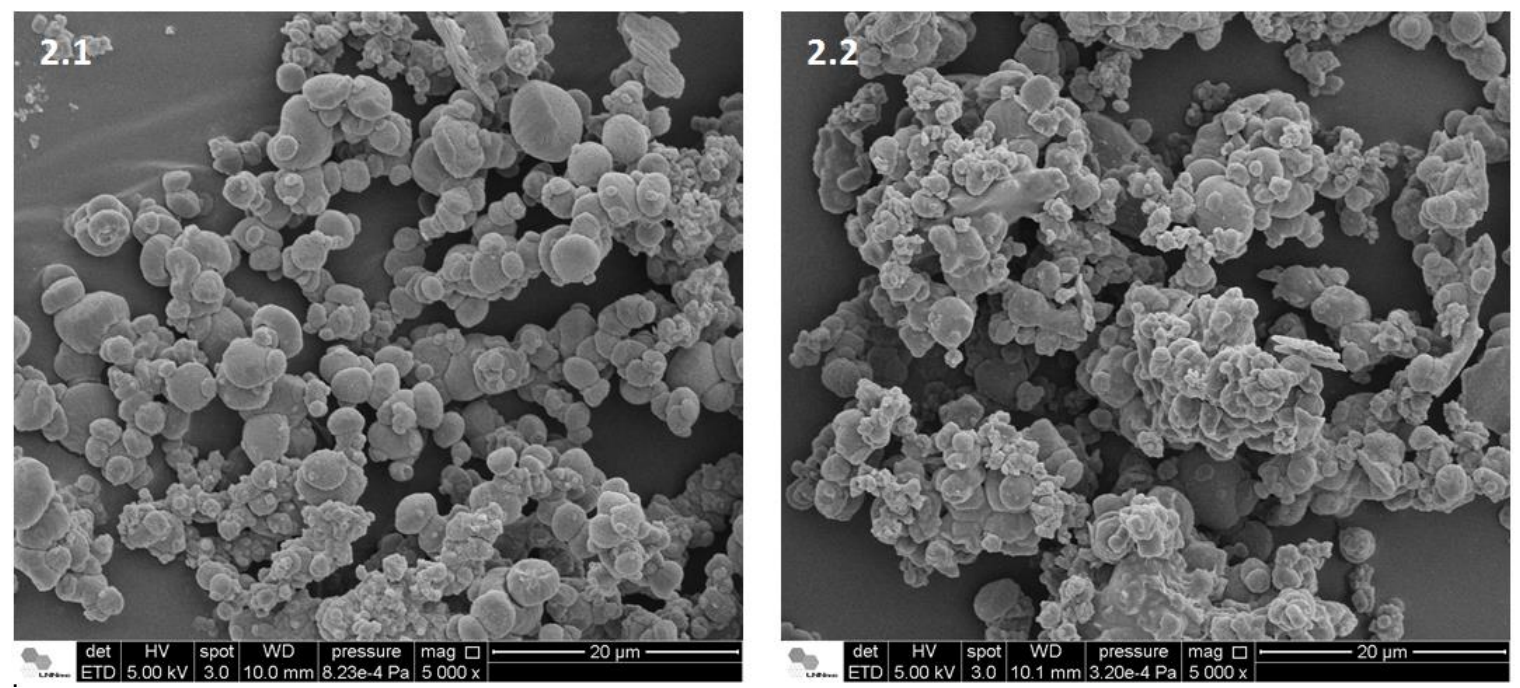

Figure 2 - FESEM micrographs (5000x magnitude) of PLLA pure particles, (2.1) $\mathrm{P}=12$ $\mathrm{MPa}, \mathrm{Q}_{\text {sol }}=0.5 \mathrm{~mL} / \mathrm{min},(2.2) \mathrm{P}=8 \mathrm{MPa}, \mathrm{Q}_{\text {sol }}=1.0 \mathrm{~mL} / \mathrm{min}$.

Regarding the precipitation of pure PLLA, according to the micrographs shown in Figure 2 (2.1 and 2.2) it was found that in both operating conditions, the particles formed exhibited spherical geometry and slightly irregular and porous surface. Under the conditions of pressure of $8 \mathrm{MPa}$ and flow rate of the feed solution of $1.0 \mathrm{~mL} / \mathrm{min}$ (Figure 2.2), the presence of agglomerated and non-homogenously distribution of particle size was observed. The combined low pressure and high flow rate may have contributed to the incomplete removal of the organic solvent present in the particles by the supercritical fluid, possibly providing supersaturation of the ethyl acetate in the vessel, which in turn may have disturbed the process of regular particle size nucleation and growth, as previously reported by Sacchetin et al. (2013).

The same behavior of the pure PLLA particles was observed in particles of PLLA + BPE. In Figure 3 (3.1 and 3.2), it is found that at the lower operating pressure, $8 \mathrm{MPa}$, the particles have become more irregular and agglomerated (Figure 3.2), unlike at the greater pressure of $10 \mathrm{MPa}$ (Figure 3.1), where one can verify that the particles are more regular, spherical and less prone to agglomeration. Possibly, the presence of residual ethyl acetate leads to this particle conformation, and further analysis to determine the content of residual solvent can confirm this tendency. For both conditions studied, a reasonable particle size distribution was observed, ranging from 0.5 to $10 \mu \mathrm{m}$. 

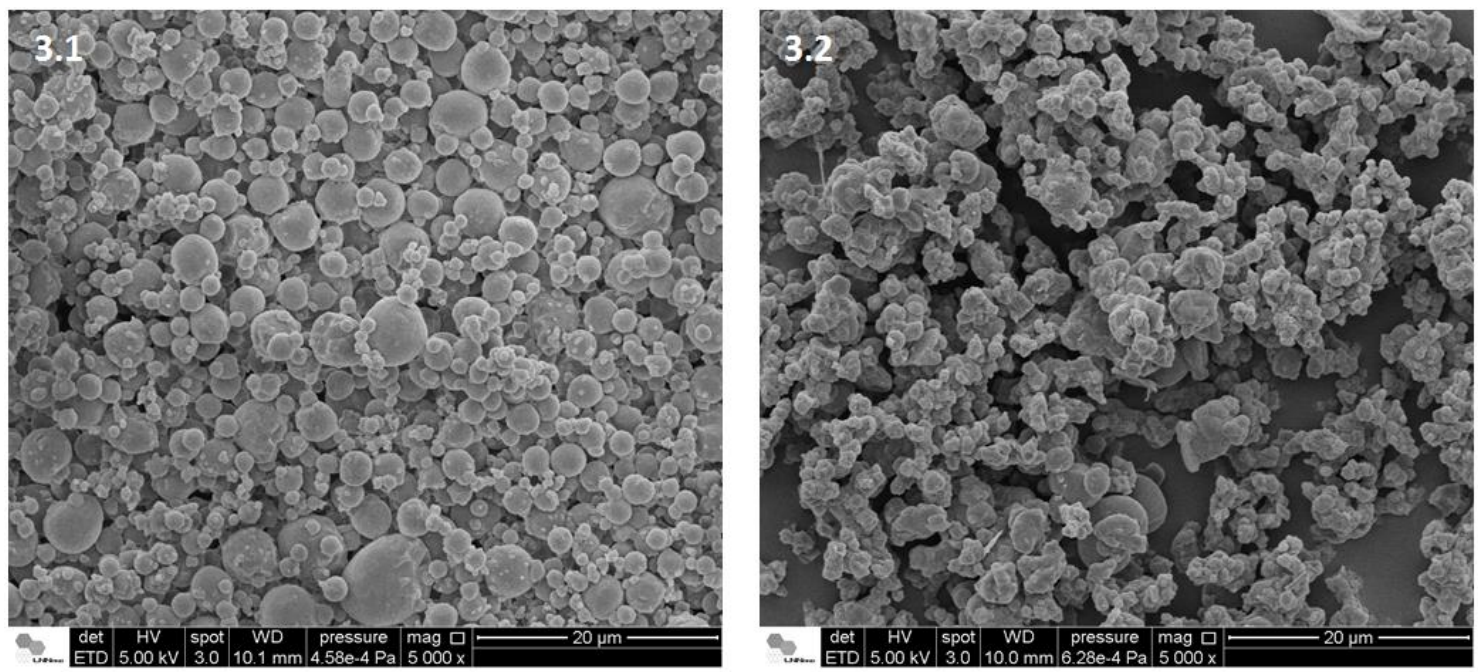

Figure 3 - FESEM micrographs (5000x magnitude) of PLLA + BPEE particles, (3.1) $\mathrm{P}=10$ $\mathrm{MPa}, \mathrm{Q}_{\text {sol }}=0.75 \mathrm{~mL} / \mathrm{min},(3.2) \mathrm{P}=8 \mathrm{MPa}, \mathrm{Q}_{\text {sol }}=0.5 \mathrm{~mL} / \mathrm{min}$.

\section{CONCLUSIONS}

The precipitation process ethanolic extract of biquinho pepper with PLLA as polymer by SAS technique was successfully applied and resulted in particles of spherical morphology and porous surface. The degree of particle agglomeration (pure PLLA and PLLA + BPE particles) was higher for the particles obtained at pressure of $8 \mathrm{MPa}$.

\section{ACKNOWLEDGEMENTS}

The authors wish to thank FAEPEX, CAPES, CNPq (Project 473342/2011-1), FAPESP (Project 2013/02203-6) for the financial support and the Brazilian National Nanotechnology Laboratory (LNNano) for the experimental support.

\section{REFERENCES}

M. J. COCERO, Á. MARTÍN, F. MATTEA and S. VARONA. Encapsulation and coprecipitation processes with supercritical fluids: Fundamentals and applications. $J$. Supercrit. Fluids, v. 47, p. 546-555, 2009.

Y. HAKUTA, H. HAYASHI and K. ARAI. Fine particle formation using supercritical fluids. Curr. Opin. Solid State Mater. Sci., v. 7, p. 341-351, 2003.

A. S. HOFFMAN. The origins and evolution of "controlled" drug delivery systems. $J$. Controlled Release, v. 132, p. 153-163, 2008.

R. HURSEL and M. S. WESTERTERP-PLANTENGA. Thermogenic ingredients and body weight regulation. Int. J. Obesity, v. 34, p. 659-669, 2010. 
J. JUNG and M. PERRUT. Particle design using supercritical fluids: Literature and patent survey. J. Supercrit. Fluids, v. 20, p. 179-219, 2001.

K. KOBATA, T. TODO, S. YAZAWA, K. IWAI and T. WATANABE. Novel Capsaicinoid-like Substances, Capsiate and Dihydrocapsiate, from the Fruits of a Nonpungent Cultivar, CH-19 Sweet, of Pepper (Capsicum annuum L.). J. Agric. Food. Chem., v. 46, p. 1695-1697, 1998.

X.-J. LUO, J. PENG and Y.-J. LI. Recent advances in the study on capsaicinoids and capsinoids. Eur. J. Pharmacol., v. 650, p. 1-7, 2011.

T. L. ROGERS, A. C. NELSEN, J. HU, J. N. BROWN, M. SARKARI, T. J. YOUNG, K. P. JOHNSTON and R. O. WILLIAMS III. A novel particle engineering technology to enhance dissolution of poorly water soluble drugs: spray-freezing into liquid. Eur. $J$. Pharm. Biopharm., v. 54, p. 271-280, 2002.

P. S. C. SACCHETIN, A. R. MORALES, Â. M. MORAES and P. D. T. V. E. ROSA. Formation of PLA particles incorporating $17 \alpha$-methyltestosterone by supercritical fluid technology. J. Supercrit. Fluids, v. 77, p. 52-62, 2013.

W. SCHLOCKER, S. GSCHLIEßER and A. BERNKOP-SCHNÜRCH. Evaluation of the potential of air jet milling of solid protein-poly(acrylate) complexes for microparticle preparation. Eur. J. Pharm. Biopharm., v. 62, p. 260-266, 2006.

D. SEMYONOV, O. RAMON, Z. KAPLUN, L. LEVIN-BRENER, N. GUREVICH and E. SHIMONI. Microencapsulation of Lactobacillus paracasei by spray freeze drying. Food Res. Int., v. 43, p. 193-202, 2010.

K. SUTOH, K. KOBATA and T. WATANABE. Stability of Capsinoid in Various Solvents. J. Agric. Food. Chem., v. 49, p. 4026-4030, 2001.

R. VEHRING. Pharmaceutical Particle Engineering via Spray Drying. Pharm. Res., v. 25, p. 999-1022, 2008.

W. WANG, G. LIU, J. WU and Y. JIANG. Co-precipitation of 10-hydroxycamptothecin and poly (l-lactic acid) by supercritical $\mathrm{CO} 2$ anti-solvent process using dichloromethane/ethanol co-solvent. J. Supercrit. Fluids, v. 74, p. 137-144, 2013. 